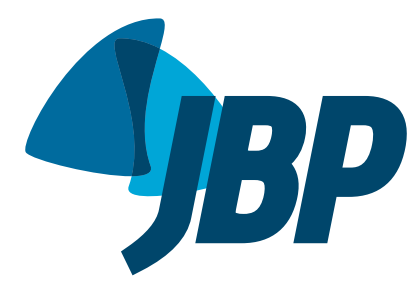

1. Fundação Hemominas, Belo Horizonte (MG) Brasil.

2. Departamento de Pediatria, Faculdade de Medicina, Universidade Federal de Minas Gerais, Belo Horizonte (MG) Brasil.

3. Grupo de Pneumologia Pediátrica Faculdade de Medicina, Universidade Federal de Minas Gerais, Belo Horizonte (MG) Brasil.

4. Departamento de Pediatria, Faculdade de Medicina, Universidade Federal de Minas Gerais, Belo Horizonte (MG) Brasil.

Submitted: 9 March 2016. Accepted: 31 October 2016.

Study carried out under the auspices of the Programa de Triagem Neonatal de Minas Gerais and at the Faculdade de Medicina, Universidade Federal de Minas Gerais, Belo Horizonte (MG) Brasil.

\section{Pulmonary function in children and adolescents with sickle cell disease: have we paid proper attention to this problem?}

\author{
Ana Karine Vieira', Cristina Gonçalves Alvim², \\ Maria Cristina Marquez Carneiro ${ }^{3}$, Cássio da Cunha Ibiapina ${ }^{4}$
}

\begin{abstract}
Objective: To evaluate pulmonary function and functional capacity in children and adolescents with sickle cell disease. Methods: This was a cross-sectional study involving 70 children and adolescents (8-15 years of age) with sickle cell disease who underwent pulmonary function tests (spirometry) and functional capacity testing (six-minute walk test). The results of the pulmonary function tests were compared with variables related to the severity of sickle cell disease and history of asthma and of acute chest syndrome. Results: Of the 64 patients who underwent spirometry, 15 (23.4\%) showed abnormal results: restrictive lung disease, in 8 (12.5\%); and obstructive lung disease, in 7 (10.9\%). Of the 69 patients who underwent the six-minute walk test, 18 (26.1\%) showed abnormal results regarding the six-minute walk distance as a percentage of the predicted value for age, and there was a $\geq 3 \%$ decrease in $\mathrm{SpO}_{2}$ in 36 patients (52.2\%). Abnormal pulmonary function was not significantly associated with any of the other variables studied, except for hypoxemia and restrictive lung disease. Conclusions: In this sample of children and adolescents with sickle cell disease, there was a significant prevalence of abnormal pulmonary function. The high prevalence of respiratory disorders suggests the need for a closer look at the lung function of this population, in childhood and thereafter. Keywords: Anemia, sickle cell; Respiratory function tests; Exercise test.
\end{abstract}

\section{INTRODUCTION}

Sickle cell disease (SCD) is the most common monogenic disease in Brazil. The number of individuals with SCD in Brazil is estimated to range from 25,000 to 30,000 . ${ }^{(1)}$ The incidence of SCD in the state of Minas Gerais, Brazil, is approximately $1: 1,400$ live births, according to the Minas Gerais State Neonatal Screening Program. ${ }^{(2)}$ The manifestations of this disease result from a predominance of sickle-shaped red blood cells, which leads to chronic hemolytic disease and vaso-occlusive phenomena. (2) SCD leads to multisystem impairment, with lung involvement being a major cause of morbidity and mortality. ${ }^{(3)}$

Some studies have been published on assessment of pulmonary function in adults with SCD, showing that the major abnormality is restrictive lung disease (RLD). ${ }^{(4,5)}$ Since the 1970 s, studies have been published on pulmonary function in the pediatric age group with $\mathrm{SCD},{ }^{(6)}$ with conflicting results being reported; however, most studies show that obstructive lung disease (OLD) is the most common abnormality. ${ }^{(7.8)}$ RLD is also common in some pediatric studies, highlighting the importance of pulmonary function testing in such children. ${ }^{(9,10)}$

Another important respiratory disease affecting children with SCD is asthma. Asthma is known to be a comorbidity impacting the course of SCD, leading to increased morbidity and mortality. ${ }^{(11,12)}$ Several studies have reported an association between asthma and an increased number of vaso-occlusive crises or acute chest syndrome (ACS) episodes. ${ }^{(11-14)}$ An association between asthma and pulmonary hypertension in children was described by Hagar et al., raising the suspicion of a shared mechanism, possibly associated with chronic hemolysis. $^{(15)}$

The mortality associated with lung disease is a serious problem in the SCD population. ${ }^{(16,17)}$ It has been demonstrated that abnormalities in pulmonary function tests are early objective signs of the development of chronic lung disease in SCD. ${ }^{(16)}$ It has recently been published that decreased $\mathrm{FEV}_{1}$ is associated with increased mortality in adults with SCD. ${ }^{(18)}$ Nevertheless, few authors in Brazil have attempted to investigate pulmonary function in patients with SCD. ${ }^{(19-21)}$ We hypothesize that the onset of pulmonary function abnormalities in SCD occurs as early as childhood. To address this challenge, the objective of the present study was to assess abnormalities in pulmonary function and functional capacity in children and adolescents with SCD, by means of spirometry and the six-minute walk test (6MWT), and to compare these abnormalities with clinical and laboratory variables in these patients.

\section{METHODS}

This was a descriptive analytical cross-sectional study. We included children and adolescents aged 8 to 15 years who were enrolled in the Minas Gerais State Neonatal 
Screening Program, in the city of Belo Horizonte, Brazil, had a confirmed diagnosis of SCD at age 1 year, and were followed in the program between February of 2013 and February of 2014. We included patients with SS phenotype or $\mathrm{S} \beta^{0}$-thalassemia-because they are known to have a more severe clinical course-who resided in the city of Belo Horizonte. We excluded patients who were unable to perform the respiratory maneuvers or the 6MWT because of cognitive or physical disability. We also excluded patients who had a severe comorbidity, such as chronic inflammatory diseases, hematological disorders, or neurological disorders.

Data were collected by interview, physical examination, and medical chart review. The interview was conducted using a semi-structured data collection protocol. The physical examination consisted of measurement of vital signs and measurement of weight and height. The medical chart review consisted of identifying clinical and laboratory data relevant to the study. Baseline hemoglobin values and leukocyte and reticulocyte counts were obtained from the arithmetic mean of three complete blood counts before hydroxyurea therapy or blood transfusions.

Medical charts were reviewed for ACS, using the following definition: development of a new pulmonary infiltrate involving at least one lung segment, accompanied by at least another symptom, such as fever, chest pain, tachypnea, wheezing, cough, or hypoxemia. ${ }^{(22)}$ The presence of a history of asthma was based on a physician diagnosis recorded in the chart and on clinical and functional criteria established by the Global Initiative for Asthma. ${ }^{(23)}$

Spirometry and the 6MWT were performed in the outpatient clinic of a SCD referral center by the same qualified pulmonary function technician. The results were interpreted by pediatric pulmonologists and reviewed by a pulmonologist specializing in pulmonary function.

Spirometry was performed with a Koko PFT spirometer (PDS Instrumentation, Inc., Louisville, CO, USA), with the patient seated and wearing a nose clip. All subjects underwent bronchodilator testing $(400 \mu \mathrm{g}$ of albuterol aerosol), and a positive result was defined as $a \geq 12 \%$ increase in $\mathrm{FEV}_{1}$ or a $>200 \mathrm{~mL}$ increase in absolute volume. (24) At least three curves were obtained. FVC, $\mathrm{FEV}_{1}$, and $\mathrm{FEF}_{25-75 \%}$ values were derived from these curves and corrected for body temperature, pressure saturated. Tests were interpreted in accordance with the Brazilian Thoracic Association (2002) Guidelines for Pulmonary Function Testing. ${ }^{(25)}$ Test results were expressed as absolute values and as a percentage of predicted according to Mallozzi. ${ }^{(26)}$ The spirometry findings were classified as normal, RLD, OLD, or nonspecific lung disease. ${ }^{(24,25)}$ PEF was measured with a Mini-Wright meter (Clement Clarke International, Essex, UK). The best of three consecutive readings was selected for analysis, using reference values provided by Polgar and Promadhat.(27) There was an interval of at least two weeks between hospital admission or blood transfusion and the test.
The 6MWT was performed in accordance with the American Thoracic Society guidelines. ${ }^{(28)}$ A wrist oximeter (Wrist 3100; Nonin Medical, Plymouth, MN, USA) and a stopwatch were used. The patient was instructed to walk as fast as possible for six minutes. The walks were supervised by the physician responsible for the study. $\mathrm{SpO}_{2}$ was measured before, during, and immediately after the walk, with care being taken to provide a minimum one-minute interval for the oximeter curve to stabilize. The distance walked in six minutes-six-minute walk distance (6MWD)-was measured in meters. Two tests were performed within 30 minutes, and when there were conflicting results between the tests, a third test was performed. A normal result was defined as a 6 MWD $>80 \%$ of predicted for age, a moderate result was defined as a 6MWD between $60 \%$ and $80 \%$ of predicted, and a severe result was defined as a $6 \mathrm{MWD}<60 \%$ of predicted. (29) A significant decrease in $\mathrm{SpO}_{2}$ (desaturation) was defined as that $\geq 3 \%$ relative to baseline. ${ }^{(30)}$

Percent predicted 6MWD was calculated following the equation proposed by Priesnitz et al.(31) Because of the lack of studies in Brazil investigating 6MWD reference values in adolescents, the equation proposed by Priesnitz et al. ${ }^{(31)}$ was also used for the patients aged 13 to 15 years.

The study population was characterized with descriptive statistics. Variables were compared with the chi-square test and Fisher's exact test. The Student's t-test was used to compare independent groups. Continuous variables were tested for normality with the Shapiro-Wilk test and/or the Kolmogorov-Smirnov test. The three spirometry-based groups were compared with ANOVA and the Kruskal-Wallis test. The level of statistical significance was set at $p<0.05$. The sample size calculation was based on the prevalence of abnormal spirometry (37\%) reported in a study conducted in Brazil. ${ }^{(19)}$ Therefore, for the sample size of our study (70 cases), the margin of estimation error is $6.3 \%$ within a $95 \%$ CI. A multivariate logistic regression analysis was performed to determine the factors associated with the outcome measure "oxygen desaturation". The baseline variables were used to build the final model. Given that the initial model included non-significant variables, it had to be reduced to test the significance of the remaining variables, that is, we sequentially removed the variable with the highest $p$ value until we reached a final model with statistically significant variables.

The project was carried out under the auspices of the Graduate Program in Child and Adolescent Health of the Federal University of Minas Gerais School of Medicine. The study was approved by the Research Ethics Committees of the Hemominas Foundation and the Federal University of Minas Gerais-the collaborative institutions involved in the study-under protocol no. CAE-08480212.6.0000.5149. The legal guardians of all participants provided written informed consent. All patients over 13 years of age provided written 
informed consent using forms written in language appropriate for their age.

\section{RESULTS}

We aimed to recruit 100 patients with SCD by contacting their families over the phone or via a primary health care clinic and inviting these families to participate. Of the targeted 100 patients, 2 had died and 1 had a disabling comorbidity. In addition, 9 families were not located and 18 declined to participate. The sample therefore consisted of 70 patients, of whom 31 (44.3\%) were male and $39(55.7 \%)$ were female. The mean age was $11 \pm 2.3$ years (range, $8-15$ years). Sixty-six individuals had the SS homozygous phenotype, whereas 4 had $S \beta^{0}$-thalassemia. Concomitant a-thalassemia trait was found in $29.1 \%$ of the participants.

Thirty-nine patients $(55.7 \%)$ were being treated with hydroxyurea, and $10(14.3 \%)$ were on a chronic transfusion regimen. Comorbid asthma was identified in 23 patients (33.3\%). In the univariate analysis, a diagnosis of asthma was not associated with the number of vaso-occlusive crises or ACS episodes. Forty-four patients (63.1\%) had at least one ACS episode, and, of those, 10 (23.1\%) experienced two or more episodes.

The descriptive statistics for the spirometric and 6MWT variables are presented in Table 1 . Spirometry was completed successfully in 64 of the 70 patients included. Two patients were unable to perform the maneuvers, and 4 did not undergo spirometry because of problems with scheduling. However, these 4 were not excluded, because they underwent the 6MWT. Of the patients who underwent spirometry, 15 (23.4\%) had abnormal pulmonary function tests. No patient was classified as having mixed obstructive-restrictive lung disease or nonspecific lung disease. The spirometry results are presented in Table 2.

The results of the univariate analysis comparing the spirometry reports with intervening variables are presented in Table 2. The patients reported as having OLD were older than were those reported as having normal spirometry results or RLD. The group of patients classified as having RLD showed lower baseline pulse oxygen saturation $(89.8 \% \pm 5.4 \%)$ than did the group of patients with OLD and the group of patients with normal spirometric results $(92.3 \% \pm 4.6 \%$ and $94.5 \%$ $\pm 4.4 \%$, respectively; $p=0.02$ ).

The 6MWT was administered to 69 patients, and 1 patient, who had undergone spirometry, declined to undergo the test. The results are presented in Table 2. The baseline $\mathrm{SpO}_{2}$ values reveal that hypoxemia was common in this population: $37(52.9 \%)$ had values < $95 \%$, with a mean of $93.6 \%$. Eighteen patients $(26.1 \%)$ had a 6 MWD $<80 \%$ of predicted for their age, and only 1 patient had a 6 MWD $<60 \%$. There was a $\geq 3 \%$ decrease in $\mathrm{SpO}_{2}$ in 36 patients (52.2\%). Univariate analysis showed that a history of ACS was the only variable of interest that had a statistically significant association with oxygen desaturation, there being an inverse association between the number of ACS episodes and the level of oxygen desaturation ( $<3 \%$ vs. $\geq 3 \%$ ), as shown in Table 3. The median (interquartile range) for ACS was 1.0 (0.0-3.0) for the group of patients with desaturation $<3 \%$ and $1.0(0.0-2.0)$ for the group of patients with desaturation $\geq 3 \%$.

In the univariate analysis, none of the variables of interest were found to have a statistically significant association with 6MWD as a percentage of predicted (Table 3). In contrast, age and hypertransfusion were found to have significant associations with absolute values of 6MWD (Table 3).

The multivariate analysis of possible predictors of oxygen desaturation is presented in Table 4. An interesting observation is that, as in the univariate analysis, a history of ACS was found to be a protective factor against oxygen desaturation during the 6MWT $(p<0.05)$. According to the measures of accuracy of the logistic regression model, the sensitivity and specificity were $48.4 \%$ and $59.0 \%$, respectively.

Table 1. Patient descriptive statistics for the spirometric and six-minute walk test variables.

\begin{tabular}{lcccc}
\multicolumn{1}{c}{ Variable } & Minimum & Maximum & Median & Mean \pm SD \\
PEF, \% of predicted & 50.0 & 106.3 & 81.0 & $79.4 \pm 13.9$ \\
FVC, \% of predicted & 63.0 & 115.0 & 85.0 & $85.0 \pm 10.6$ \\
FEV $_{1}, \%$ of predicted & 57.0 & 117.0 & 78.5 & $78.7 \pm 10.7$ \\
$\mathrm{FEV}_{1} / \mathrm{FVC}$ ratio & 84.0 & 112.0 & 0.86 & $0.86 \pm 0.05$ \\
$\mathrm{FEF}_{25-75 \%}$ & 43.0 & 125.0 & 72.0 & $76.0 \pm 17.6$ \\
${\text { Baseline } \mathrm{SaO}_{2}, \%}_{\text {Final SaO }}, \%$ & 78.0 & 99.0 & 94.0 & $93.6 \pm 4.8$ \\
Desaturation, \% & 72.0 & 99.0 & 91.0 & $89.3 \pm 7.6$ \\
6MWD, $\mathrm{m}$ & -3.0 & -26.0 & -2.0 & $-4.6 \pm 6.3$ \\
6MWD, \% of predicted & 380 & 114.8 & 520.0 & $527.3 \pm 51.4$ \\
Baseline HR, bpm & 56.4 & 120 & 85.1 & $84.9 \pm 8.3$ \\
Final HR, bpm & 60.0 & 175.0 & 87.0 & $87.9 \pm 13.7$ \\
Baseline RR, breaths/min & 91.0 & 28.0 & 131.0 & $132.4 \pm 18.8$ \\
Final RR, breaths/min & 12.0 & 36.0 & 16.0 & $18.0 \pm 3.4$ \\
\hline
\end{tabular}

6MWD: six-minute walk distance; HR: heart rate; and RR: respiratory rate. 
Table 2. Comparative statistics across three spirometry-based patient groups $(N=64)$ for the variables of interest. ${ }^{a}$

\begin{tabular}{|c|c|c|c|c|}
\hline \multirow[t]{2}{*}{ Variables } & \multicolumn{3}{|c|}{ Groups } & \multirow[t]{2}{*}{ p* } \\
\hline & $\begin{array}{l}\text { Normal } \\
(n=49)\end{array}$ & $\begin{array}{c}\text { RLD } \\
(n=8)\end{array}$ & $\begin{array}{c}\text { OLD } \\
(n=7)\end{array}$ & \\
\hline Age, years & $11.0 \pm 2.3$ & $11.9 \pm 1.7$ & $13.3 \pm 1.5$ & 0.045 \\
\hline \multicolumn{5}{|l|}{ Gender, \% } \\
\hline Male & 44.9 & 25.0 & 71.4 & \multirow[t]{2}{*}{$0.241^{* *}$} \\
\hline Female & 55.1 & 75.0 & 28.6 & \\
\hline Baseline hemoglobin, g/dL & $8.1 \pm 1.2$ & $7.4 \pm 0.5$ & $8.0 \pm 0.5$ & 0.151 \\
\hline Fetal hemoglobin, $\%$ & $11.2 \pm 8.4$ & $11.7 \pm 9.8$ & $12.1 \pm 6.7$ & 0.875 \\
\hline Baseline leukocytes $/ \mu \mathrm{L}$ & $14.542 \pm 2.988$ & $14.222 \pm 2.680$ & $14.269 \pm 4.931$ & 0.979 \\
\hline Reticulocytes, \% & $14.6 \pm 5.6$ & $13.6 \pm 3.9$ & $14.9 \pm 6.6$ & 0.604 \\
\hline $\mathrm{SaO}_{2}, \%$ & $94.5 \pm 4.6$ & $89.8 \pm 5.4$ & $92.3 \pm 4.4$ & 0.020 \\
\hline ACS episodes & $1.7 \pm 2.1$ & $1.4 \pm 1.5$ & $0.4 \pm 0.5$ & 0.245 \\
\hline Asthma, \% & 28.6 & 37.5 & 57.1 & $0.274^{* *}$ \\
\hline Hydroxyurea therapy, \% & 55.1 & 28.6 & 57.1 & $0.457^{* *}$ \\
\hline Hypertransfusion, \% & 16.3 & 0.0 & 16.7 & $0.667^{* *}$ \\
\hline a-thalassemia trait, \% & 30.8 & 0.0 & 28.6 & $0.638^{* *}$ \\
\hline \multicolumn{5}{|l|}{ Desaturation, $\%$} \\
\hline$<3$ & 45.8 & 50.0 & 28.6 & \multirow[t]{2}{*}{$0.693^{* *}$} \\
\hline$\geq 3$ & 54.2 & 50.0 & 71.4 & \\
\hline $6 \mathrm{MWD}, \%$ of predicted & $84.1 \pm 7.4$ & $84.5 \pm 11.1$ & $86 \pm 9.3$ & $0.879^{* *}$ \\
\hline
\end{tabular}

RLD: restrictive lung disease; OLD: obstructive lung disease; ACS: acute chest syndrome; and 6MWD: six-minute

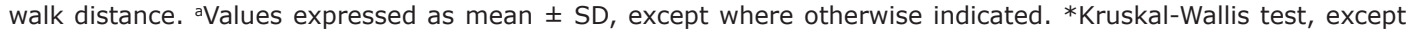
where otherwise indicated. **Fisher's exact test.

\section{DISCUSSION}

The present study showed that pulmonary function, as measured by spirometry, was abnormal in approximately one fourth of the patients with $S C D$, the most common abnormality being RLD. A high rate of desaturation during the 6MWT was found, which was not associated with 6MWD or with spirometry-assessed pulmonary function.

A history of asthma was present in one third of the patients, which is double the prevalence observed in the population of children and adolescents in the city of Belo Horizonte (17.8\%), according to the International Study of Asthma and Allergies in Childhood. ${ }^{(32)}$ A similar prevalence was found in a retrospective cohort study conducted by Williams et al., ${ }^{(33)}$ who demonstrated that $35.9 \%$ of the patients had a diagnosis of asthma and that a decline in $\mathrm{FEV}_{1}$ as a percentage of predicted is associated with progression to pulmonary dysfunction. These findings underscore the need for the recognition of asthma, as well as the importance of longitudinal follow-up of pulmonary function, in this population.

Lung disease patterns in SCD are heterogeneous and can change over time. In the present study, $11 \%$ of the patients were found to have OLD; of those, $57 \%$ had a clinical diagnosis of asthma. Similarly, in a cohort of patients studied by Boyd et al. ${ }^{(12)} 13 \%$ were found to have OLD, and of those $13 \%, 77 \%$ had a diagnosis of asthma; in addition, an association was found between OLD and increased rates of hospitalization for pain or ACS. Another important study showed that $63 \%$ of the patients with asthma had normal spirometry results and that only $40 \%$ of the patients classified as having OLD had a history of asthma. ${ }^{(34)}$ These findings indicate that there may be several inflammatory mechanisms involved in the genesis of airway obstruction in SCD. The prevalence of OLD (12.5\%) found in the present study was also similar to those found in other studies, such as the ones conducted by Boyd et al. and by Tassel et al., both of which reported a prevalence of $13 \%$. ${ }^{(12,35)}$

One of the limitations of the present study is the lack of whole-body plethysmographic confirmation of RLD. Longitudinal studies have shown that there is a decline in lung volume and pulmonary function over the years in children with SCD; however, the pathophysiology of respiratory disorders in childhood has not been fully elucidated. ${ }^{(9,35)}$ This decline was reported in a cohort study by Lunt et al., ${ }^{(36)}$ who demonstrated that a history of ACS episodes was the only independent factor associated with reduced lung volumes. Some biological markers, such as leukocytosis, are known to be associated with SCD severity, but their relationship with pulmonary function has only recently been the subject of investigation. ${ }^{(37)}$ A study by Tassel et al. ${ }^{(35)}$ showed that the decline in pulmonary function in childhood was directly associated with two markers of severity of the underlying disease: leukocytosis and hemolysis. In the present study, an association was noted between baseline hypoxemia and RLD, indicating that this group of patients may tend to experience greater disease severity, given that baseline hypoxemia is associated with the degree of anemia and of hemolysis. ${ }^{(30)}$

The 6MWT has grown in importance in the follow-up of SCD because studies in adults show a relationship between 6MWD and tricuspid regurgitant jet velocity, which is used to estimate pulmonary artery systolic pressure on echocardiography. This finding suggests 
Table 3. Comparative statistics ( $N=69$ patients) between the outcome measures (oxygen desaturation and six-minute walk distance) and the variables of interest. ${ }^{*}$

\begin{tabular}{|c|c|c|c|c|c|}
\hline \multirow[t]{2}{*}{ Variable } & \multicolumn{2}{|c|}{ Desaturation, \% } & \multirow[t]{2}{*}{ p } & \multicolumn{2}{|c|}{ 6MWD } \\
\hline & $\begin{aligned}< & 3 \\
(n & =33)\end{aligned}$ & $\begin{aligned} & \geq 3 \\
(n & =36)\end{aligned}$ & & $\%$ of predicted & Absolute value, $\mathrm{m}$ \\
\hline Age, years & $11.6 \pm 2.4$ & $11.0 \pm 2.3$ & 0.345 & $\begin{array}{l}r=-0.15^{\dagger} \\
p=0.224\end{array}$ & $\begin{array}{l}r=0.38^{\dagger} \\
p=0.001\end{array}$ \\
\hline Gender, \% & 43.8 & 47.2 & $0.774^{*}$ & & \\
\hline $\begin{array}{l}\text { Male } \\
\text { Female }\end{array}$ & 56.3 & 52.8 & & $\begin{array}{l}85.4 \pm 8.0 \\
83.8 \pm 8.6 \\
p=0.434\end{array}$ & $\begin{array}{c}525.2 \pm 54.4 \\
518.9 \pm 48.9 \\
p=0.623\end{array}$ \\
\hline Baseline hemoglobin, $\mathrm{g} / \mathrm{dL}$ & $7.9 \pm 1.1$ & $8.1 \pm 1.1$ & 0.378 & $\begin{array}{l}r=-0.17^{\dagger} \\
p=0.167\end{array}$ & $\begin{array}{l}r=-0.15^{\dagger} \\
p=0.249\end{array}$ \\
\hline Fetal hemoglobin, \% & $10.1 \pm 8.7$ & $13.0 \pm 8.1$ & 0.194 & $\begin{array}{l}r=0.08^{\dagger} \\
p=0.544\end{array}$ & $\begin{array}{l}r=-0.02^{\dagger} \\
p=0.878\end{array}$ \\
\hline Baseline $\mathrm{SaO}_{2}, \%$ & $93.6 \pm 5.0$ & $93.6 \pm 4.7$ & 0.983 & $\begin{array}{l}r=-0.10^{\dagger} \\
p=0.429\end{array}$ & $\begin{array}{l}r=-0.23^{\dagger} \\
p=0.057\end{array}$ \\
\hline ACS episodes & $2.1 \pm 2.5$ & $0.9 \pm 0.9$ & 0.024 & $\begin{array}{l}r=-0.11^{\dagger} \\
p=0.389\end{array}$ & $\begin{array}{l}r=0.15^{\dagger} \\
p=0.229\end{array}$ \\
\hline Asthma, \% & & & $0.386^{* *}$ & & \\
\hline Yes & 40.6 & 30.6 & & $82.7 \pm 9.0$ & $528.3 \pm 55.3$ \\
\hline No & 59.4 & 69.4 & & $\begin{array}{l}85.5 \pm 7.8 \\
p=0.210\end{array}$ & $\begin{array}{c}518.2 \pm 49.1 \\
p=0.456\end{array}$ \\
\hline Hydroxyurea therapy, \% & 64.5 & 44.4 & $0.100^{* *}$ & & \\
\hline Yes & 35.5 & 55.6 & & $84.9 \pm 9.3$ & $519.2 \pm 51.6$ \\
\hline No & & & & $\begin{array}{l}84.4 \pm 7.0 \\
p=0.781\end{array}$ & $\begin{array}{c}525.5 \pm 52.0 \\
p=0.619\end{array}$ \\
\hline Hypertransfusion, \% & 9.7 & 17.1 & $0.484^{* * *}$ & & \\
\hline Yes & 90.3 & 82.9 & & $80.5 \pm 11.9$ & $480.0 \pm 56.6$ \\
\hline No & & & & $\begin{array}{l}85.4 \pm 7.6 \\
p=0.266\end{array}$ & $\begin{array}{c}528.3 \pm 48.4 \\
p=0.036\end{array}$ \\
\hline a-thalassemia trait, \% & 39.1 & 23.3 & $0.214^{* *}$ & & \\
\hline Yes & 60.9 & 76.7 & & $86.5 \pm 5.7$ & $530.0 \pm 37.2$ \\
\hline No & & & & $\begin{array}{l}84.3 \pm 8.0 \\
p=0.253\end{array}$ & $\begin{array}{c}520.0 \pm 55.8 \\
p=0.455\end{array}$ \\
\hline $6 \mathrm{MWD}, \%$ of predicted & $84.6 \pm 9.3$ & $85.0 \pm 7.7$ & 0.849 & & \\
\hline
\end{tabular}

ACS: acute chest syndrome; and 6MWD: six-minute walk distance. *Student's t-test for independent samples, except where otherwise indicated. $* *$ Chi-square test. $* * *$ Fisher's exact test. 'Pearson's correlation coefficient for continuous variables ( $r$ value) and its respective $p$ value.

Table 4. Multivariate logistic regression analysis for identification of factors associated with six-minute walk test desaturation ( $\geq 3 \%$ ).

\begin{tabular}{lccc}
\multicolumn{1}{c}{ Variable } & $\mathbf{D}$ & (Wald) chi-square & $\mathbf{p}$ \\
Initial model & & & \\
$\quad$ Intercept & -1.116 & 0.157 & 0.692 \\
Gender & 0.213 & 0.134 & 0.715 \\
Baseline hemoglobin & 0.183 & 0.355 & 0.551 \\
$\mathrm{SaO}_{2}$ & 0.170 & 0.058 & 0.810 \\
$\mathrm{Asthma}$ & -0.158 & 0.065 & 0.799 \\
Hydroxyurea therapy & 0.085 & 0.016 & 0.901 \\
Acute chest syndrome & -0.309 & 2.024 & 0.155 \\
6MWD, \% of predicted & 0.003 & $<0.001$ & 0.996 \\
Final model & & & \\
Intercept & 0.570 & 2.642 & 0.104 \\
Acute chest syndrome & -0.393 & 4.207 & 0.040 \\
\hline
\end{tabular}

6MWD: six-minute walk distance.

that the 6MWT can be used as a noninvasive measure of severity of pulmonary hypertension and functional capacity in this population. ${ }^{(38)}$ Studies in the pediatric population remain scarce. An important study of children and adolescents carried out by Minniti et al. observed that elevated tricuspid regurgitant jet velocity was associated with a decline in $\mathrm{SpO}_{2}$ during the 6MWT but not with a shorter 6MWD, as occurs 
in adults. ${ }^{(39)}$ In addition, a study conducted by Waltz et al. reported a decline in $\mathrm{SpO}_{2}$ during the 6MWT in patients with $\mathrm{HbSS}$ genotype (in $34 \%$ ) and in patients with $\mathrm{HbSC}$ (in 18\%). ${ }^{(40)}$

The 6MWD as a percentage of predicted for age was below normal in $26.1 \%$ of the patients; however, severe impairment was found in only 1 patient. A similar result was reported by Dedeken et al., (29) who found that $30 \%$ of a sample of 46 children and adolescents had abnormal 6MWT. The role of the 6MWT in children and adolescents with SCD has yet to be fully determined; however, it seems that $>3 \%$ desaturation during the 6MWT may serve as an early marker of development of pulmonary hypertension in this population. ${ }^{(30)}$

In the present study, $52 \%$ of the patients had a significant decrease in post-6MWT pulse $\mathrm{SpO}_{2}$, a prevalence that is higher than that reported in other studies, such as the ones by Waltz et al.(40) (34\%) and by Campbell et al. ${ }^{(30)}(8 \%)$, the latter of which involved patients with other phenotypes (SC, SD, and others). This difference needs to be confirmed in other studies in Brazil, because the present study is the first of its kind in the country and shows the importance of functional assessment in this population.

In the logistic regression analysis, a history of ACS was surprisingly found to be a protective factor against oxygen desaturation during the 6MWT. This is likely a reflection of further treatment intensification in the patients who experienced ACS, including hydroxyurea therapy and/or chronic transfusion. This finding was also reported in a study that sought to understand the differences between adults and children with pulmonary hypertension. ${ }^{(15)}$ That study demonstrated that a history of ACS was a protective factor against pulmonary hypertension in the adult population. ${ }^{(15)}$ In the present study, the low sensitivity and specificity of the multivariate analysis model do not allow the elucidation of this complex pathophysiological process, and it is possible that clinical variables other than the ones we measured are associated.

As far as limitations of this study are concerned, we acknowledge that it was conducted in a single blood bank and was cross-sectional and that important tests, such as echocardiography and whole-body plethysmography were not performed, because they were not part of the research protocol. Therefore, further longitudinal studies with a large number of centers are warranted to verify the results obtained here and to determine which clinical and laboratory variables in SCD are of importance in clinical practice, because, in the literature, there is a lack of data on the factors actually influencing the development of lung function impairment.

Finally, the present study showed a relevant prevalence of abnormal pulmonary function and of significantly decreased $\mathrm{SpO}_{2}$ during the 6MWT in a sample of patients aged 8 to 15 years, indicating the early onset of chronic lung disease in SCD. The common finding of obstructive and of restrictive pulmonary function abnormalities in this population underscores the need for a closer look at lung function, with the aid of objective measures, such as spirometry, in childhood and thereafter, in order to screen for chronic lung disease.

In summary, the data presented here, indicating that the prevalence of pulmonary function abnormalities in patients with SCD may be higher in Brazil, emphasize how important it is that studies of lung function in this population be conducted in the country. This subject must be researched extensively and thoroughly, including incorporating other methods of assessment, such as whole-body plethysmography and echocardiography, and is a large field of research yet to be explored in Brazil.

\section{REFERENCES}

1. Cançado RD, Jesus JA. Sickle cell disease in Brazil [Article in Portuguese]. Rev Bras Hematol Hemoter. 2007;29(3):204-6.

2. Fernandes $A P$, Januário JN, Cangussu CB, Macedo DL, Viana MN Mortality of children with sickle cell disease: a population study. J Pediatr (Rio J). 2010;86(4):279-84. http://dx.doi.org/10.2223/ jped.2005

3. Darbari DS, Kple-Faget P, Kwagyan J, Rana S, Gordeuk VR, Castro 0 . Circumstances of death in adult sickle cell disease patients. Am J Hematol. 2006;81(11):858-63. http://dx.doi.org/10.1002/ajh.20685

4. Klings ES, Wyszynski DF, Nolan VG, Steinberg MH. Abnorma pulmonary function in adults with sickle cell anemia. Am J Resp Crit Care Med. 2006;173(11):1264-9. http://dx.doi.org/10.1164/ rccm.200601-1250C

5. Young RC Jr, Rachal RE, Reindorf CA, Armstrong EM, Polk OD Jr Hackney RL Jr, et al. Lung function in sickle cell hemoglobinopathy patients compared with healthy subjects. I Nat Med Assoc. 1988;80(5):509-14

6. Wall MA, Platt OS, Strieder DJ. Lung function in children with sickle cell anemia. Am Rev Respir Dis. 1979;120(1):210-4

7. Koumbourlis AC, Hurlet-Jensen A, Bye MR. Lung function in infants with sickle cell disease. Pediatr Pulmonol. 1997;24(4):277-81. http://dx.doi.org/10.1002/(SICI)1099-0496(199710)24:4<277::AIDPPUL6>3.0.CO;2-H

8. Santoli F, Zerah F, Vasile N, Bachir D, Galacteros F, Atlan G. Pulmonary function in sickle cell disease with or without acute chest

syndrome. Eur Resp J. 1998;12(5):1124-9. http://dx.doi.org/10.1183/ 09031936.98.12051124

9. Boyd JH, DeBaun MR, Morgan WJ, Mao J, Strunk RC. Lower airway obstruction is associated with increased morbidity in children with sickle cell disease. Pediatr Pulmonol. 2009;44(3):290-6. http://dx.doi. org/10.1002/ppul.20998

10. MacLean JE, Atenafu E, Kirby-Allen M, MacLusky IB, Stephens $D$, Grasemann $\mathrm{H}$, et al. Longitudinal decline in lung volume in a population of children with sickle cell disease. Am J Resp Crit Care Med. 2008;178(10):1055-9. http://dx.doi.org/10.1164/rccm.20070812190C

11. Boyd JH, Macklin EA, Strunk RC, DeBaun MR. Asthma is associated with acute chest syndrome and pain in children with sickle cell anemia. Blood. 2006;108(9):2923-7. http://dx.doi.org/10.1182/ blood-2006-01-011072

12. Boyd JH, Macklin EA, Strunk RC, DeBaun MR. Asthma is associated with increased mortality in individuals with sickle cell anemia. Haematologica. 2007;92(8):1115-8. http://dx.doi.org/10.3324/ haematol. 11213

13. Bernaudin F, Strunk RC, Kamdem A, Arnaud C, An P, Torres M, et al. Asthma is associated with acute chest syndrome, but not with an increased rate of hospitalization for pain among children in France with sickle cell anemia: a retrospective cohort study. Haematologica. 2008;93(12):1917-8. http://dx.doi.org/10.3324/haematol.13090

14. Glassberg J, Spivey JF, Strunk R, Boslaugh S, DeBaun MR 
Painful episodes in children with sickle cell disease and asthma are temporally associated with respiratory symptoms. J Pediatr Hematol Oncol. 2006;28(8):481-5. http://dx.doi.org/10.1097/01 mph.0000212968.98501.2b

15. Hagar RW, Michlitsch JG, Gardner J, Vichinsky, EP, Morris CR Clinical differences between children and adults with pulmonary hypertension and sickle cell disease. Br J Haematol. 2008;140(1):10412

16. Hamideh D, Alvarez O. Sickle cell disease related mortality in the United States (1999-2009). Pediatr Blood Cancer. 2013;60(9):1482-6. http://dx.doi.org/10.1002/pbc.24557

17. Powars D, Weidman JA, Odom-Maryon T, Niland JC, Johnson C. Sickle cell chronic lung disease: prior morbidity and the risk of pulmonary failure. Medicine (Baltimore). 1988;67(1):66-76. http:// dx.doi.org/10.1097/00005792-198801000-00005

18. Low forced expiratory volume is associated with earlier death in sickle cell anemia. Blood. 2015;126(13):1544-50. http://dx.doi. org/10.1182/blood-2015-05-644435

19. Souza LC, Viegas CA. Quality of sleep and pulmonary function in clinically stable adolescents with sickle cell anemia. J Bras Pneumol. 2007;33(3):275-81. http://dx.doi.org/10.1590/S180637132007000300008

20. Fonseca CS, Araújo-Melo CA, Carvalho RM, Barreto-Neto J, Araújo $\mathrm{JG}$, Cipolotti R. Lung function in patients with sickle cell anemia. Rev Paul Pediatr. 2011;29(1):85-90. http://dx.doi.org/10.1590/S010305822011000100014

21. Ohara DG, Ruas G, Walsh IA, Castro SS, Jamami M. Lung function and six-minute walk test performance in individuals with sickle cell disease. Braz J Phys Ther. 2014;18(1):79-87. http://dx.doi. org/10.1590/S1413-35552012005000139

22. Castro O, Brambilla DJ, Thorington B, Reindorf CA, Scott RB, Gillette $P$, et al. The acute chest syndrome in sickle cell disease: incidence and risk factors. The Cooperative Study of Sickle Cell Disease. Blood. 1994:84(2):643-9.

23. Global Initiative for Asthma [homepage on the Internet]. Bethesda Global Initiative for Asthma. [cited 2016 Feb 01]. Global Strategy for Asthma Management and Prevention 2012. [Adobe Acrobat document, 128p.]. Available from: http://www.ginasthma.org/local/ uploads/files/GINA_Report_March13.pdf

24. Lung function testing: selection of reference values and interpretative strategies. American Thoracic Society. Am Rev Respir Dis. 1991;144(5):1202-18. http://dx.doi.org/10.1164/ajrccm/144.5.1202

25. Sociedade Brasileira de Pneumologia e Tisiologia. Diretrizes para testes de função pulmonar. J Pneumol. 2002;28(Suppl 3):S1-S238.

26. Mallozi MC. Valores de referência para espirometria em crianças e adolescentes, calculados a partir de uma amostra da cidade de São Paulo [thesis]. São Paulo: Escola Paulista de Medicina/Universidade Federal de São Paulo; 1995.

27. Polgar G, Promadhat V. Pulmonary function testing in children: techniques and standards. Philadelphia: WB Saunders; 1971.

28. ATS Committee on Proficiency Standards for Clinical Pulmonary Function Laboratories. ATS statement: guidelines for the six-minute walk test. Am J Resp Crit Care Med. 2002;166(1):111-7. http:// dx.doi.org/10.1164/ajrccm.166.1.at1102
29. Dedeken L, Chapusette R, Lê PQ, Heijmans C, Devalck C, Huybrechts $\mathrm{S}$, et al. Reduction of the six-minute walk distance in children with sickle cell disease is correlated with silent infarct: results from cross-sectional evaluation in a single center in Belgium. PloS One. 2014; 9(9):e108922. http://dx.doi.org/10.1371/journal.pone.0108922

30. Campbell A, Minniti CP, Nouraie M, Arteta M, Rana S, Onyekwere $\mathrm{O}$, et al. Prospective evaluation of haemoglobin oxygen saturation at rest and after exercise in paediatric sickle cell disease patients. Br J Haematol. 2009;147(3):352-9. http://dx.doi.org/10.1111/j.13652141.2009.07854.x

31. Priesnitz CV, Rodrigues GH, Stumpf Cda S, Viapiana G, Cabral CP, Stein RT, et al. Reference values for the 6-min walk test in healthy children aged 6-12 years. Pediatric Pulmonol. 2009; 44(12):1174-9. http://dx.doi.org/10.1002/ppul.21062

32. Solé D, Wandalsen GF, Camelo-Nunes IC, Naspitz CK. Prevalence of symptoms of asthma, rhinitis, and atopic eczema among Brazilian children and adolescents identified by the International Study of Asthma and Allergies in Childhood (ISAAC) - Phase 3. J Pediatr (Rio J). 2006;82(5): 341-6. http://dx.doi.org/10.1590/S0021 75572006000600006

33. Williams SN, Nussbaum E, Yoonessi L, Morphew T, Randhawa I. Progression and prognostic indicators of bronchial disease in children with sickle cell disease. Lung. 2014;192(3):385-93. http://dx.doi. org/10.1007/s00408-014-9572-y

34. Koumbourlis AC, Lee DJ, Lee A. Longitudinal changes in lung function and somatic growth in children with sickle cell disease. Pediatric Pulmonol. 2007;42(6):483-8. http://dx.doi.org/10.1002/ ppul.20601

35. Tassel C, Arnaud C, Kulpa M, Fleurence E, Kandem A, Madhi F, et al. Leukocytosis is a risk factor for lung function deterioration in children with sickle cell disease. Respir Med. 2011;105(5):788-95. http:// dx.doi.org/10.1016/j.rmed.2010.12.024

36. Lunt A McGhee E, Sylvester K, Rafferty G, Dick M, Rees D, et al. Longitudinal assessment of lung function in children with sickle cell disease. Pediatr Pulmonol. 2016;51(7):717-23. http://dx.doi. org/10.1002/ppul.23367

37. Okpala I. Leukocyte adhesion and the pathophysiology of sickle cell disease. Curr Opin Hematol. 2006;13(1):40-4. http://dx.doi. org/10.1097/01.moh.0000190108.62414.06

38. Anthi A, Machado RF, Jison ML, Taveira-Dasilva AM, Rubin LJ, Hunter $\mathrm{L}$, et al. Hemodynamic and functional assessment of patients with sickle cell disease and pulmonary hypertension. Am J Resp Crit Care Med. 2007;175(12):1272-9. http://dx.doi.org/10.1164/ rccm.200610-14980C

39. Minniti CP, Sable C, Campbell A, Rana S, Ensing G, Dham N, et al. Elevated tricuspid regurgitant jet velocity in children and adolescents with sickle cell disease: association with hemolysis and hemoglobin oxygen desaturation. Haematologica. 2009;94(3):340-7. http://dx.doi. org/10.3324/haematol.13812

40. Waltz $X$, Romana M, Lalanne-Mistrih ML, Machado RF, Lamarre $Y$, Tarer $\mathrm{V}$, et al. Hematologic and hemorheological determinants of resting and exercise-induced hemoglobin oxygen desaturation in children with sickle cell disease. Haematologica. 2013:98(7):103944. http://dx.doi.org/10.3324/haematol.2013.083576 